\title{
ENGAGING IN CHIT-CHAT (AND ALL THAT)
}

\author{
A review of Why We Talk: The Evolutionary Origins of Language \\ by Jean-Louis Dessalles (translated by James Grieve). Oxford University Press \\ (2007), 395 pages, £35.00 (\$55.00), ISBN: 0199276233 (hardback).
}

FIONA M. JORDAN

Centre for the Evolution of Cultural Diversity, Department of Anthropology, University College London, London WC1H 0BW, UK

E-mail: f.jordan@ucl.ac.uk

Why do we talk? Just to chat, to indulge in a little bit of information sharing? JeanLouis Dessalles addresses the question of why we talk with an argument that is, in the end, the stuff of everyday life. Accounts of the evolutionary origins of language often explore how the development of specific cognitive, perceptual, or motor abilities in the hominin lineage paved the way for spoken language. In this book, Desalles takes his account of evolutionary origins of language out of brains and bodies and into the social realm. Social life as a communicative selection pressure is not a new idea, as DUNBAR (1996) sketched with his grooming and gossip hypothesis, and as implied by "theory of mind" arguments. Drawing on research in linguistics and evolutionary anthropology, here Desalles proposes that we talk because, as hominids, we live our lives in social groups where we gain status from pointing out salient and correct information in our environment. But talk is not cheap: it is costly signalling.

ZAHAVI's (1975) "Handicap Principle" is the familiar expression of costly signalling theory (CST), which indicates that honest signalling of trait quality can be an evolutionary stable strategy even when it is possible to deceive receivers thus, previously inexplicable "costly" signals or traits may evolve. In evolutionary accounts of human behaviour, CST has become the new black. Recent years have seen CST advanced to explain (for instance) the evolution of cooperative behaviour, religious displays, and foraging strategies. So how does the idea fare when applied to the evolution of language?

To lead us there, Dessalles does not find use for the common idea that human language is a form of reciprocal communication. Why not? A game-theoretical argument implies that speakers should not give away accurate information for free if listeners can either "cheat" and refuse to return the favour, or can ignore the 
information altogether if the speaker is communicating untruths. Costly signalling solves this paradox by seeing language as an honest indicator of a quality individual attribute, that is, the cognitive ability to discriminate important information about the world around us, and then use that information to facilitate social relationships. Simply put, being able to say "I saw it first" - and be correct - helped our ancestors to win friends and influence people.

Why We Talk is not a textbook, but the first third, in which we are invited to explore the phylogenetic and comparative context of human language, is an engaging wander through familiar topics such as animal communication and crosscultural variation in language. Dessalles discusses "the slow and the fast" (p. 118) aspects of evolutionary change, linking debates about gradual versus rapid evolution in language faculty to questions of natural selection. This then sets up the middle third of the book on the functional anatomy of speech. Much of this material may be unfamiliar to non-linguists, but the key point is simple: parts of speech and language show evidence of functional design, so Dessalles suggests we may profitably seek adaptive explanations. The final third of the book is ethological, looking at conversational behaviour and the demands that ultra-social behaviours place on, and are fulfilled by, a language faculty. For those of us who are often deterred from language evolution studies, daunted by the formal mathematics of grammar, this natural history approach to spontaneous conversation is refreshing. This is the evolution of language as language, rather than tied firmly to the development of faculties such as bipedalism, tool use, or theory of mind.

Noteworthy in Dessalles' argument is his appeal to "local optima" in evolutionary change. Features of phonology, the limited functionality of a protolanguage, and an ability for thematic representation (made possible by syntax) are all hill-climbing strategies that "won" in the environment of increasing social and political complexity that characterised hominid evolution. The chapters devoted to dismantling concepts of Panglossian progress in language are perhaps a little belaboured. However, evolutionary psychologists and anthropologists can always revisit the lesson that natural selection builds structures that will suffice their purpose, often jury-rigged and co-opted rather than planned meticulously from the ground up. This is not to say that we do not find coherent design in nature - just that we should not expect it, and the more complex the trait, the less we might expect best practice. Note that this does not commit us to exaptation arguments for example, Dessalles does not suggest that human vocal language was re-jigged from primate vocalisations. But by stressing the importance of local optima, we are free to consider evolutionary scenarios in which multiple and mosaic selection regimes may have done work, which may help us begin to integrate what the "chaotic state of the field, and the number of ever-proliferating theories" about language evolution (BICKERTON 2007, p. 524).

We are promised an exploration of co-evolutionary pathways in the evolution of language, but it must be said that strong arguments using, for instance, theoretical gene-culture co-evolution frameworks (e.g. DURHAM 1991), or the 
concept of niche construction (e.g. ODLING-SMEE, LALAND and FELDMAN 2003) are not made explicit, although the reader familiar with those may extrapolate their own versions using the fertile material in the book. Two factors may explain this lack. Firstly, there is a degree of false division between biology and culture in the early chapters: it appears that Dessalles feels that to quash the notion that "language is a cultural construct" is to argue a version of cultural construction with foresight and purpose. Cultural evolutionary processes are not by definition directed or invented, nor should we expect (p. 49) a society with a complex linguistic system to be similarly complex in social structure (whatever that should mean). Similarly, an evolutionary process such as natural selection does not prima facie imply solely biological (i.e. genetic) evolution; selection pressures on aspects of language may have been so strong as to canalise initially cultural behaviours. As an active researcher of cultural and linguistic evolution, albeit from a phylogenetic perspective, I amused myself by substituting "cultural evolution" in each instance of the phrase "biological evolution" - and the vast majority of arguments still made sense. This leads to the second and much more minor point that this volume is a translation, and there may be subtleties in evolutionary discourse that are perhaps clouded (somewhat ironically) by language differences.

My main difficulty with Why We Talk was that while the structure of the book was a straightforward linear argument, the thesis was kept frustratingly under wraps until the end. In virtually all chapters Desalles throws up the question of why we should have the language faculties he describes, only to steer us away for one more chapter: "but first, we need to address X". For fans of thriller novels, the suspense tactic may be appealing, but in this context one sometimes requires seventh-order intentionality to hold the arguments in play. A simple sketch of the final arguments before the weight of evidence was discussed would have made the book easier to follow: in its absence, I would recommend that readers skim the final chapters in advance.

Despite the extensive cautionary discussion of adaptationist excesses in the first part, the natural history approach to conversation in the final part does fall back heavily on adaptation-friendly verbal arguments. In this respect, the costly signalling argument fails to immediately convince, as Dessalles does not deal comprehensively with the non-signal aspects of language. It (CST) remains a contender, but one of many plausible arguments. There is no startling new theory here, but an intriguing and clearly presented set of hypotheses waiting for further formal testing (the author has already begun such a program via computational modelling). Broadly aimed at researchers and graduate students in linguistics, anthropology, psychology and evolutionary biology, Why We Talk is a welcome new contribution to the study of language evolution simply because it is about language: it concentrates on linguistic data, explores language functions - and makes us think about what we're actually doing when we engage in chit-chat (and all that). 


\section{REFERENCES}

BICKERTON, D. (2007): Language evolution: A brief guide for linguists. Lingua, 117, 510-526.

DunBAR, R. I. M. (1996): Grooming, Gossip, and the Evolution of Language. London: Faber and Faber.

Durham, W. H. (1991): Coevolution: Genes, Culture, and Human Diversity. Stanford: Stanford University Press.

Odling-Smee, F. J., Laland, K. N. and Feldman, M. (2003): Niche Construction: The Neglected Process in Evolution. Princeton, NJ: Princeton University Press.

ZAHAVI, A. (1975): Mate selection: A selection for a handicap. Journal of Theoretical Biology, 53, 205-214. 